\title{
GW23-e1444 EFFECT OF CIGARETTE SMOKE EXTRACT ON THE EXPRESSION OF THROMBOMODULIN IN HUMAN ENDOTHELIAL CELLS
}

doi:10.1136/heartjnl-2012-302920af.2

Wei Yujie, Li Yi, Liu Huiliang. Department of Cardiology, General Hospital of Chinese People's Armed Police Forces

Objectives Cigarette smoking cause triggering of coronary thrombosis. However, the mechanism by which smoking cause arterial thrombosis remains unknown. Thrombomodulin (TM) is constitutively expressed on the endothelial cell surface. TM has a critical effect on anticoagulation and anti-inflammation. It is not clear the way leading to intravascular thrombosis whether cigarette smoking affect the expression of TM. Therefore, we studied the expression of thrombomodulin in Human Umbilical Vein Endothelial Cells (HUVECs) under different cigarette smoke extract conditions.

Methods CSE was prepared by a modification of Nakamura's method. HUVEC were isolated and cultured in low serum endothelial cell medium. The third generation of HUVECs were incubated respectively with $0,0.5 \%, 1 \%, 2.5 \%$ and $5 \%$ CSE for $6 \mathrm{~h}$ or exposed to $5 \%$ CSE for $0,6,12,24,48 \mathrm{~h}$ to determine the expression changes of TM protein and mRNA expression in HUVECs. RT-PCR and Flow cytometric analysis techniques were used for detecting TM mRNA and protein.

Results After 6-h exposure to CSE, the protein level of of endothelial TM in different concentrations $(0.5 \%, 1 \%, 2.5 \%, 5 \%)$ reduced significantly $(60.39 \pm 2.03,56.55 \pm 1.47,55.82 \pm 3.32,53.70 \pm 3.95)$ compared to control group $(67.45 \pm 1.22) \quad(\mathrm{p}<0.01)$. and the mRNA level of endothelial TM also decreased significantly $(0.1859 \pm 0.0139,0.1776 \pm 0.0156,0.0853 \pm 0.0136,0.0571 \pm 0.0123)$ compared to control group $(0.2550 \pm 0.0345) \quad(p<0.01)$. After stimulation with $5 \%$ CSE for $0,6,12,24,48 \mathrm{~h}$, the levels of TM mRNA and protein decreased over time and reached the peak at $12 \mathrm{~h}(0.0244 \pm 0.0181,30.51 \pm 0.61)$, which were significantly lower than that of control group $(0.1558 \pm 0.0267,66.04 \pm 1.56)$ $(\mathrm{p}<0.001)$.

Conclusions CSE significantly decreased the expression of TM in a time- and concentration-dependent fashion in HUVECs. That suggests cigarette smoking maybe according this way to lead to intravascular thrombosis. 